\title{
PROTEÇÃo PENAL AO PATRIMONIO CULTURAL E A PAISAGEM NO DIREITO BRASILEIRO: INAPLICABILIDADE DO PRINCÍPIO DA INSIGNIFICÂNCIA E RECONHECIMENTO DA SOLIDARIEDADE INTERGERACIONAL \\ CRIMINAL PROTECTION OF CULTURAL HERITAGE AND LANDSCAPE IN THE BRAZILIAN LAW: NON-APPLICABILITY OF THE PRINCIPLE OF INSIGNIFICANCE AND RECOGNITION OF INTERGENERATIONAL SOLIDARITY
}

\author{
${ }^{1}$ Maraluce Maria Custódio \\ ${ }^{2}$ Carolina Carneiro Lima
}

\section{RESUMO}

Busca-se analisar a proteção penal do patrimônio cultural e da paisagem e demonstrar que não se tutela apenas aqueles mas, sobretudo o liame subjetivo que os conecta com o ser humano, garantindo identidade e pertencimento ao meio. $\mathrm{O}$ desenvolvimento sustentável é o marco teórico, e o método utilizado é o analítico-dedutivo, pretendendo responder qual o fundamento jurídico para a impossibilidade de se aplicar o princípio da insignificância e garantir solidariedade intergeracional na proteção do patrimônio cultural material e da paisagem na tutela penal brasileira. A hipótese aventada indica uma necessidade da proteção integral penal ao patrimônio cultural e à paisagem.

Palavras-chave: Princípio da solidariedade intergeracional, Meio ambiente cultural, Princípio da insignificância, Tutela penal, Paisagem

\begin{abstract}
It aims to analyze the criminal protection of cultural heritage and landscape and show the need to protect all the subjective bond that connects them with the human being. ensuring in the future the relationship of identity and belonging can endure. Sustainable development is the theoretical framework, and the method used is the analytical-deductive, intending to answer the failure to apply the principle of insignificance and ensure intergenerational solidarity in the protection of cultural heritage material and the landscape in Brazilian criminal protection. The mooted hypothesis indicates a need for criminal full protection to the cultural heritage and landscape.
\end{abstract}

Keywords: Principle of intergenerational solidarity, Cultural environment, Principle of insignificance, Criminal responsibility, Landscape

\footnotetext{
${ }^{1}$ É Professora Permanente da Pós-Graduação em Direito da Escola Superior Dom Helder Câmara, EDSHC - MG, (Brasil). Mestre em Direito e Doutora em Geografia pela Universidade Federal de Minas Gerais, UFMG - MG, (Brasil). E-mail : maralucem@hotmail.com

${ }^{2}$ Mestranda em Direito Ambiental e Desenvolvimento Sustentável pela Escola Superior Dom Helder Câmara. EDSHC - MG, (Brasil).E-mail : carolcarneirolima@yahoo.com.br
} 


\section{INTRODUÇÃO}

A tutela penal do patrimônio cultural e da paisagem possui características específicas e exige um compromisso mais sério com esta fração do meio ambiente. $\mathrm{O}$ direito penal e com ele as leis penais extravagantes são considerados a ultima ratio da proteção jurídica conferida a algum bem. A seara criminal somente atua quando as demais esferas não se apresentem efetivas no resguardo dos bens de relevante e significativa importância para a sociedade.

A proteção penal de referidos bens surgiu em razão da importância dada ao meio ambiente pela Constituição da República Federativa do Brasil de 1988 que se apresenta como espelho da consciência ambiental da sociedade brasileira e está preceituada, principalmente, na Lei 9.605/1998, abrangendo todo patrimônio cultural, seja ele material ou imaterial, histórico, artístico e paisagístico.

O texto objetiva analisar os matizes e as particularidades envolvidas na garantia de uma proteção mais efetiva do meio ambiente cultural material e da paisagem apontando a inaplicabilidade do direito penal mínimo e do princípio da insignificância em razão da incompatibilidade desses parâmetros com o objeto jurídico, penalmente protegido. $\mathrm{O}$ artigo texto mostra-se importante para a conformação de uma solidariedade intergeracional, fundamental para a manutenção da memória e a edificação da identidade do povo brasileiro.

A proteção do patrimônio cultural e da paisagem encontra sustentáculo no caput do art. 225 da Constituição da Repúbica Federativa do Brasil quando menciona que o meio ambiente, e com ele todas as suas classificações, é essencial para uma sadia qualidade de vida. Tutela-se não apenas o objeto materializado, mas, sobretudo, o liame que o conecta com o próprio ser humano. Assim, o seu resguardo deve possuir amplitude necessária e a mesma seriedade conferidas ao patrimônio natural.

O problema que se busca responder está contido no fundamento jurídico para a inaplicabilidade do princípio da insignificância e na consequente garantia da solidariedade intergeracional característica precípua do patrimônio cultural material e da paisagem pretendida pela sua tutela penal.

Para a pesquisa usa-se o princípio do desenvolvimento sustentável como marco teórico, pois é a norma que concilia o avanço tecnológico e social com a manutenção de um meio ambiente equilibrado que possa ser usado pela geração do presente e garantido para as gerações do futuro. O método é o analítico-dedutivo que se dá por meio de pesquisas bibliográficas, interdisciplinares e legislativas. 
Discorre-se, para tanto, sobre a relação do meio ambiente, de maneira geral, com o direito ambiental; desenvolvendo-se a abordagem até alcançar o parâmetro jurídico de excepcionalidade existente na proteção penal, como ultima ratio, e a tutela do patrimônio cultural material e da paisagem. Segue-se para a abordagem do princípio da solidariedade intergeracional e a incompatibilidade com a corrente de pensamento do direito penal mínimo. Finda-se com a inaplicabilidade do princípio da insignificância, pois o que se protege é o liame subjetivo que conecta o ser humano com os objetos patrimônio cultural e paisagem que não podem ser quantificadas.

Nas considerações finais aponta-se para uma hipótese que consiste na proteção integral da paisagem e do patrimônio cultural com o devido respeito às suas características inerentes. A atenção a ser dispensada a consiste na manutenção do objeto com seus traços identificadores e no liame valorativo que o liga ao ser humano, estabelecendo a representatividade social.

\section{TUTELA PENAL DO MEIO AMBIENTE}

O parâmetro brasileiro de análise e de conceituação do meio ambiente hodiernamente encontra-se na Constituição da República Federativa do Brasil (CRFB). A norma ampliou expressivamente a tutela ambiental quando comparado com os textos constitucionais anteriores. Ficou conhecida como uma constituição ambientalista tal a extensão da proteção que conferiu a este bem jurídico, de especial significado para a humanidade.

É considerada a Carta Política mais avançada do Planeta em matéria ambiental, podendo ser denominada de "verde", em razão da importância e da proteção dirigida patrimônio ambiental do país (MILARÉ, 2014). O Texto Maior captou com precisão a noção nacional crescente acerca das questões que envolvem uma vida digna e uma sadia qualidade de vida. Trouxe em seu corpo permanente a

\footnotetext{
consciência de que é preciso aprender a conviver harmoniosamente com a natureza traduzindo em vários dispositivos aquilo que pode ser considerado um dos sistemas mais abrangentes e atuais do mundo sobre a tutela do meio ambiente. A dimensão conferida ao tema não se resume, a bem ver, aos dispositivos concentrados especialmente no Capítulo VI do Título VIII, dirigido à Ordem Social - alcança da mesma forma inúmeros outros regramentos insertos ao longo do texto nos mais diversos títulos e capítulos, decorrentes do conteúdo multidisciplina da matéria. (MILARÉ, 2014, p. 169/170).
} 
A definição jurídica de meio ambiente é "o conjunto de condições, leis, influências e interações de ordem física, química e biológica, que permite, abriga e rege a vida em todas as suas formas" encontrando-se preceituada no art. $3^{\circ}$, inciso I da Lei 6.938/81, Lei de Políticas Nacionais do Meio Ambiente (BRASIL, 1981). Trata-se de um conceito amplo que abriga em si todas as classificações necessárias para se compreender o ambiente em sua completude. As classificações originam-se da imprescinbilidade de se especificar os objetos protegidos e conferir análises mais precisas e eficientes.

Doutrinariamente, idêntica situação ocorre. Vislumbra-se uma interconexão entre os fatores formadores e sua utilização por toda a sociedade, sendo, o meio ambiente, considerado o "conjunto de bens caracterizados como tais e destinados ao usufruto da comunidade, é bastante diferenciado por força da concepção holística do meio ambiente, que compreende muitos outros elementos além daqueles que são estritamente chamados naturais" (MILARÉ, 2014, p. 507).

Qualquer que seja a classificação adotada, tripartite, quádrupla ou quíntupla ${ }^{1}$, o meio ambiente cultural, um dos objetos do presente estudo, encontra-se descrito.

Dentro das leis, não há um conceito de paisagem, restando apenas o conceito dado, por portaria do IPHAN, em 2009, que na verdade é um conceito de paisagem cultural, mas que cumpre com a finalidade de fixar e difundir a lógica da paisagem como algo não apenas ambiental. A portaria define paisagem cultural como "uma porção peculiar do território nacional representativa do processo de interação do homem com o meio natural à qual a vida e a ciência humana imprimiram marcas ou atribuíram valores" (IPHAN, 2009, p.35). Este conceito tenta contemplar os três elementos da paisagem (objeto, observador e percepção), seguindo a linha conceitual da UNESCO, mais ainda se revela um pouco vago e não parece contemplar ou dar indícios de se preocupar com a paisagem imaterial. Mas é inegável que a paisagem é direito que deve ser garantido, apesar de dinâmica, sempre deve estar concatenada às mudanças impostas pela sociedade. Trata-se de questão que deve ser considerada, para que não ocorra lesão ao direito das comunidades envolvidas, inclusive, no seu autorreconhecimento e nos seus referenciais, envolvendo aspectos de identidade e bem-estar. Deve-se sempre lembrar que a paisagem é formada pelos elementos

\footnotetext{
$1 \mathrm{O}$ meio ambiente é uno e todas as suas divisões ou classificações interligam-se. Todas as suas unidades pertencem à biosfera e estão em constante interação com o ser humano. Apenas para facilitar o seu estudo e a sua tutela é que são realizadas subdivisões, possuindo divisões doutrinárias mais minuciosas e outras mais simples.

A divisão tripartite é a mais simples, apresentando o meio ambiente como natural, artificial e cultural.

Existe, porém, outras classificações mais minuciosas fragmentando seu estudo em quatro ou até em cinco subdivisões. A primeira descreve o meio ambiente como artificial, natural, cultural e do trabalho. A segunda, mais ampla de todas, é a que acrescenta, ainda, o meio ambiente genético, já dando sinais de pretender incluir, também, o meio ambiente digital (FIORILLO; CONTE, 2012).

Nosso foco é mostrar a importância do meio ambiente cultural que não é olvidado por nenhuma das divisões, subdivisões ou classificações existentes.
} 
ambientais sejam naturais, sejam culturais. Daí, proteção ambiental pretendida pela CRFB que se estende à paisagem é preventiva e não apenas repressiva, fato que se estende para todas as esferas protetivas, seja administrativa, civil ou penal.

O que se pretende é a não configuração do dano, da lesão e a manutenção do ambiente e da paisagem adequados para que possam ser desfrutados pela geração do presente e pelas gerações vindouras. Esta característica é marcada pela existência de uma verdadeira tutela antecipada penal com a criação de crimes de perigo concreto, de perigo abstrato, de mera conduta e de normas penais em branco. Tal conformação mostra a edificação de um corpo normativo voltado para a prevenção e não para a repressão (FIORILLO; CONTE, 2012).

Importante observar que o princípio da prevenção norteia toda a proteção ambiental e da paisagem, e não só a sua fração criminal. O que se busca é evitar o dano que, em matéria ambiental, sobretudo em matéria ambiental material, pode ser de impossível reversibilidade ou de reversibilidade muito difícil e no caso da paisagem, se não se conjugar a mudança com o interesse da sociedade, será de impossível reversibilidade. Assim, o objetivo precípuo é a não configuração da lesão e a manutenção da integridade dos bens culturais e da paisagem para deleite de toda comunidade ao longo dos tempos.

A imposição de sanções penais para agressões ao ambiente e paisagem é reflexo da importância de ambos para a sociedade e do grau de reprovabilidade que se confere ao dano e ao desrespeito a este bem jurídico pelo corpo social.

A conformação criminal da proteção ambiental e da paisagem tem supedâneo jurídico-formal na CRFB em seu art. $225, \S 3^{\circ 2}$. Buscou-se uma tutela mais efetiva, estendendo sua abrangência para as pessoas jurídicas, uma vez que a personalidade jurídica é a principal responsável pelos impactos ambientais mais expressivos verificados no Planeta nos últimos tempos (MONTOLLI, 2014). Depreende-se que os constituintes atribuíram aos delitos ambientais uma relevância excepcional, uma importância incomum (FREITAS, 2002), sendo que os legisladores infraconstitucionais não tiveram outra opção se não acompanhar a larga proteção dispensada ao meio ambiente e reflexo dos ideais sociais para o Estado de Direito brasileiro.

\footnotetext{
2 Art. 225. Todos têm direito ao meio ambiente ecologicamente equilibrado, bem de uso comum do povo e essencial à sadia qualidade de vida, impondo-se ao Poder Público e à coletividade o dever de defendê-lo e preservá- lo para as presentes e futuras gerações. $[\ldots]$

$\S 3^{\circ}$ As condutas e atividades consideradas lesivas ao meio ambiente sujeitarão os infratores, pessoas físicas ou jurídicas, a sanções penais e administrativas, independentemente da obrigação de reparar os danos causados. (BRASIL, 1988).
} 
Não se pode desconectar a importância das empresas para o desenvolvimento tecnológico e para uma melhor qualidade de vida de maneira imediata, mas também, não podendo esquecer que toda atividade antrópica gera impactos e necessita de matérias primas básicas, retiradas do ambiente, para se elaborar o produto industrial, sem olvidar da destruição sistemática de várias paisagens ao longo do processo de desenvolvimento. Pois, todo o ciclo de criação dos produtos tecnológicos e industriais altera o ambiente, podendo repercutir no patrimônio cultural e na paisagem, com mudança nas suas características essenciais ou mesmo destruição.

A necessidade de punição criminal mostra-se importante porque o risco imposto ao meio ambiente e à paisagem é um risco apresentado para a qualidade de vida e para a saúde de toda a população, bens jurídicos relevantes e que devem ser peremptoriamente protegidos. Neste instante, uma indagação já merece destaque e resposta: como um dano ao patrimônio cultural material ou à paisagem pode afetar a vida e a saúde dos cidadãos?

A resposta a essa questão, entendida a questão como um ponto controvertido de fato e de direito, já aponta a diretriz científica a ser percorrida pelo presente estudo. A lesão a ambos atinge a saúde psíquica das pessoas, violenta a sua identidade, o pertencimento, a sua origem, a sua história. Uma pessoa sem referenciais é menos segura, menos produtiva e se desvincula do local onde vive, perdendo o senso de comunidade.

O ser humano, da mesma maneira que o meio ambiente, é plúrimo, é holístico - não é formado apenas de matéria e, sim, de subjetividade. O patrimônio cultural é a reunião do patrimônio artístico com o patrimônio histórico, bem como a paisagem podem ter importância local, regional, nacional ou mundial, de acordo com a repercussão de seu significado. "Os bens efetivos da sadia qualidade de vida são os bens fundamentais à garantia da dignidade da pessoa humana, o que significa que ter uma vida saudável é ter uma vida com dignidade" (MONTOLLI, 2014, p. 301).

Não restam dúvidas, então, de que a tutela penal é importante para a efetiva proteção do meio ambiente cultural e da paisagem e que eles estão intimamente ligados a uma sadia qualidade de vida como objetivado pelo art. 225, caput da CRFB.

A tutela penal, conforme mencionado, está prevista no indicativo constitucional do art. $225, \S 3^{\circ}$, e nas necessidades existenciais do ser humano, sendo abordada de maneira "uniforme, clara e ordenada" (PRADO, 2001, p. 31), na Lei $\mathrm{n}^{\circ}$ 9.605, de 12 de fevereiro de 1998, em seu art. $3^{\circ}$, in verbis: 
As pessoas jurídicas serão responsabilizadas administrativa, civil e penalmente conforme o disposto nesta Lei, nos casos em que a infração seja cometida por decisão de seu representante legal ou contratual, ou de seu órgão colegiado, no interesse ou benefício da sua entidade. (BRASIL, 1998).

Salienta o legislador infraconstitucional, no parágrafo único deste artigo, que a responsabilidade da pessoa jurídica não exclui a das pessoas físicas, autoras, coautoras ou partícipes no fato, sendo, evidente o objetivo de uma abordagem precisa e plena dos fatos ilícitos que envolvam o meio ambiente e por extensão a paisagem.

A responsabilização criminal da pessoa jurídica foi descrita em norma extravagante, pois sua inserção no Código Penal seria complicada, uma vez que quebra o paradigma jurídico da responsabilidade penal pautada unicamente em aspectos subjetivos, ampliando-o, agora, para vertentes objetivas. Salta aos olhos a modificação e evolução da proteção de que atinge com a disposição constitucional de 1988 e efetivada com a promulgação da Lei dos Crimes Ambientais (Lei n ${ }^{\circ}$ 9.605/98). Houve, na verdade, uma atualização na "percepção do papel das empresas no mundo contemporâneo", pois as lesões ambientais não são mais praticadas em pequena escala, mas, sobretudo, de forma corporativa (MACHADO, 2008, p. 700), buscando o uso do ambiente para a obtenção de lucros particulares.

\section{Rompeu-se, consequentemente,}

[...] com a tradição secular do Direito Penal brasileiro, baseado no caráter subjetivo da responsabilidade. Não se encontrará, certamente, doutrina que a justifique. A sua grande força reside no argumento prático e real de que nos crimes ambientais mais graves se chega a identificar o verdadeiro responsável. A responsabilidade penal sempre recai no motorista do caminhão, no piloto do barco ou no vigia noturno da grande empresa. Os caminhos que dividem tarefas e funções nas corporações são impenetráveis. Isso fez com que os países mais adiantados do mundo passassem a punir penalmente as pessoas jurídicas nos crimes contra a ordem econômica e nos praticados contra o meio ambiente. (FREITAS, 2002, p. 213).

O advento da proteção penal do meio ambiente e da extensão dessa tutela para as pessoas jurídicas não se dá apenas na Lei nº 9.605/1998 é oriunda da mudança de paradigma realizada pela Constituição da República, ensejando a edição de diversos outros corpos normativos. O enfoque maior é dado para a lei descrita alhures em razão da sua importância especial para o regramento das bases jurídicas criminais do meio ambiente que desponta quando as outras responsabilizações não são efetivas em permitir uma prevenção e uma reparação integral e tempestiva das demandas fático-jurídicas. 
A Lei de Crimes Ambientais não é somente penal ${ }^{3}$. Possui dispositivos administrativos, que na verdade eram a completude do texto original, elaborados Instituto Brasileiro do Meio Ambiente e dos Recursos Naturais Renováveis (IBAMA), responsável pela submissão do projeto de lei ao Congresso Nacional. Suas normas de cunho administrativo foram oportunas e garantiram uma atuação de maior eficiência (FREITAS, 2002).

O direito penal atinge apenas os bens jurídicos mais relevantes socialmente e que não conseguiram uma proteção suficiente pelos outros ramos do direito. Desta forma, observa-se que a tutela penal ocorre somente para casos importantíssimos, primeiro porque precisa tratarse de um bem jurídico, ou seja, bem atrelado ao critério de utilidade, cujo valor social configurese essencial para a convivência harmônica e pacífica dos seres humanos em sociedade e segundo as demais esferas do direito devem ter fracassado em, sozinhas ou isoladamente, garantirem a adequada tutela a eles (FIORILLO; CONTE, 2012).

O meio ambiente é bem jurídico relevante para a vida e a sua vertente cultural não é diferente, bem como seu conjunto que forma o elemento material da paisagem. O patrimônio cultural e a paisagem configuram elementos essenciais ao ser humano, seus anseios, medos, desafios e conquistas. Mostra em si a natureza descortinada pela arte, pela história que lhes dão pertencimento. Por esta razão são elementos desprovidos de valor mensurável, afastando a possibilidade de aplicação do princípio da insignificância e mostrando o seu valor como referencial vivido para as gerações do futuro.

O patrimônio cultural é a concretização da essência do ser humano das gerações antecedentes, mantido vivo para a geração do presente, enquanto a paisagem é a concretização da sociedade como comunidade, pois traz a noção de pertencimento ao meio passado por gerações de membros que vivem e viveram naquele local. Esta, por sua vez, deverá, em verdadeira solidariedade intergeracional, garantir que ambas perdurem e sirvam de exemplo e amparo para o futuro.

\footnotetext{
3 “A Lei 9.605/98 tem como inovações marcantes não utilização do encarceramento como norma geral para as pessoas físicas criminosas, a responsabilidade penal das pessoas jurídicas e a valorização da intervenção da Administração Pública, através de autorizações, licenças e permissões." (MACHADO, 2008, p. 696/697).
} 
Nesse sentido, a proteção do patrimônio cultural e da paisagem é oriunda da função social de ambos, a tutela não se verifica no patrimônio objetivo descrito, mas, sim, na sua suprapatrimonialidade (MIRANDA, 2006). O valor protegido pelo Direito Penal no patrimônio cultural e na paisagem está além das coisas corpóreas ostentadas no mundo real. Protege-se todo um vínculo existencial, incorpóreo, mas que se configura como essencial para a construção de uma sociedade que pretende sentir-se pertencente a um território, a um povo e a um tempo histórico ${ }^{4}$.

Eis os componentes elementares para se conceber a tutela penal do meio ambiente cultural e da paisagem.

\section{A ULTIMA RATIO E OS ILÍCITOS CONTRA O PATRIMÔNIO CULTURAL MATERIAL E A PAISAGEM}

A proteção penal do meio ambiente é fundamental para a compreensão inequívoca de que o ambiente encontra-se inserido nos bens jurídicos de valor mais relevante socialmente.

Para ser considerado bem cultural, é condição sine qua non que seja representativo de uma ação, identidade ou memória de diferentes grupos sociais. São traços que o particularizam e trazem a proteção em favor do interesse da coletividade (OLIVEIRA JÚNIOR, 2014). A ascensão foi importante para se proteger o patrimônio cultural material que não deve ser visto apenas como um objeto e, sim, como o reflexo da história e da arte de uma geração.

Já a paisagem, em termos de definição na atualidade, no Brasil, existem vários conceitos apresentados pelas diversas ciências, uns mais conhecidos como os da geografia, outros menos, como os da psicologia. Todavia, em ambas as esferas, estes conceitos não têm um efeito de vinculação social como um todo.

Essa realidade se faz sentir quanto à proteção da paisagem, pois, apesar de garantida pelo sistema legal, ainda não se configura plenamente no Brasil especialmente por ainda não existir, no âmbito jurídico brasileiro, um conceito legal de paisagem que a conceba de forma totalizante, em sua feição mais moderna (CUSTODIO, 2014). Apesar de se ter consciência que também a paisagem tem traços que a particularizam e que traz a proteção em favor do interesse da coletividade.

\footnotetext{
4 A história segundo Marc Bloch, historiador francês do século XX e um dos fundadores da Escola dos Annales é homem no tempo - conceito importante para se compreender a importância do patrimônio histórico e artístico (cultural), pois vincula o passado remoto ou recente ao presente conduzindo nossos referenciais de identidade e pertencimento para a construção do futuro. Tudo isto se conecta ao conceito de meio ambiente e à sadia qualidade de vida psíquica do ser humano. (BLOCH, 1997).
} 
A tutela penal é reputada como a ultima ratio, atuando somente quando as outras esferas do direito não mais consigam garantir a proteção do bem jurídico que, também, não será qualquer bem. O bem jurídico penalmente protegido é aquele que se mostra importante e necessário “à própria sobrevivência da sociedade” (GRECO, 2009, p. 4).

A proteção penal está descrita, no caso do patrimônio cultural e da paisagem, precipuamente, nos arts. 62 a 65 da Lei $n^{\circ} 9.605 / 98^{5}$ e no art. $165^{6}$ do Código Penal, objetivando tutelar os bens que são "extremamente valiosos, não do ponto econômico, mas sim político" (GRECO, 200, p. 4). O Direito Penal pretende uma proteção ampla e integral para que estes bens perdurem, sendo conhecidos e admirados intergeracionalmente.

O cuidado e o zelo com o patrimônio cultural e principalmente da paisagem é dever e responsabilidade de todos e "tal missão é essencial para que a humanidade evolua em sua busca de conhecimento, liberdade e qualidade de vida, de forma harmônica e respeitosa com a natureza, a história e a memória de nossos antepassados, que produziram a cultura que nos cerca" (MIRANDA, 2009, p. 23).

\section{Seção IV}

Dos Crimes contra o Ordenamento Urbano e o Patrimônio Cultural

Art. 62. Destruir, inutilizar ou deteriorar:

I - bem especialmente protegido por lei, ato administrativo ou decisão judicial;

II - arquivo, registro, museu, biblioteca, pinacoteca, instalação científica ou similar protegido por lei, ato administrativo ou decisão judicial:

Pena - reclusão, de um a três anos, e multa.

Parágrafo único. Se o crime for culposo, a pena é de seis meses a um ano de detenção, sem prejuízo da multa.

Art. 63. Alterar o aspecto ou estrutura de edificação ou local especialmente protegido por lei, ato administrativo ou decisão judicial, em razão de seu valor paisagístico, ecológico, turístico, artístico, histórico, cultural, religioso, arqueológico, etnográfico ou monumental, sem autorização da autoridade competente ou em desacordo com a concedida:

Pena - reclusão, de um a três anos, e multa.

Art. 64. Promover construção em solo não edificável, ou no seu entorno, assim considerado em razão de seu valor paisagístico, ecológico, artístico, turístico, histórico, cultural, religioso, arqueológico, etnográfico ou monumental, sem autorização da autoridade competente ou em desacordo com a concedida:

Pena - detenção, de seis meses a um ano, e multa.

Art. 65. Pichar ou por outro meio conspurcar edificação ou monumento urbano: Pena - detenção, de

3 (três) meses a 1 (um) ano, e multa.

$\S 1^{\mathrm{O}}$ - Se o ato for realizado em monumento ou coisa tombada em virtude do seu valor artístico, arqueológico ou histórico, a pena é de 6 (seis) meses a 1 (um) ano de detenção e multa.

$\S 2^{\mathrm{O}}$ - Não constitui crime a prática de grafite realizada com o objetivo de valorizar o patrimônio público ou privado mediante manifestação artística, desde que consentida pelo proprietário e, quando couber, pelo locatário

ou arrendatário do bem privado e, no caso de bem público, com a autorização do órgão competente e a observância das posturas municipais e das normas editadas pelos órgãos governamentais responsáveis pela preservação e conservação do patrimônio histórico e artístico nacional. (BRASIL, 1998).

6 Dano em coisa de valor artístico, arqueológico ou histórico

Art. 165 - Destruir, inutilizar ou deteriorar coisa tombada pela autoridade competente em virtude de valor artístico, arqueológico ou histórico:

Pena - detenção, de seis meses a dois anos, e multa. (BRASIL, 1940). 
O patrimônio cultural e a paisagem no Brasil encontram-se protegidos no art. $216^{7}$ da CRFB em rol exemplificativo, até porque não poderia ser taxativo ante seu dinamismo. A manutenção de uma interpretação ampla é essencial para que ambos sejam expressão do movimento do ser humano no tempo. Ambos necessitam do ser humano do presente para ganhar e renovar seu significado. "Os limites da História são, paradoxalmente, o espaço da esperança e do sonho: propiciar diferentes versões do passado é, ao mesmo tempo, aquilo que nos coloca em movimento que nos mantém na luta" (CHUVA, 2011, p. 48).

A proteção penal é valiosa porque gera mais temor e as lesões devem ser, ao máximo, evitadas em razão da dificuldade ou impossibilidade de reparação em razão da sua unicidade e irrepetibilidade, traços específicos e marcantes tanto do patrimônio cultural quanto da paisagem.

Ambos, bens culturais e paisagem, possuem potencialidade atemporal e tem o condão de interligar gerações, rompendo as barreiras do passado, do presente e do futuro, perpetuando-se para toda a coletividade brasileira (OLIVEIRA JÚNIOR, 2014).

Assim, interligam-se as gerações em verdadeira solidariedade e reconhecimento, demonstrando que mais que a matéria protegida (objeto protegido), resguarda-se o sinalagma emocional que constrói a cidadania. Fica evidente que não há expressividade econômica nesta proteção. Há apenas a exteriorização material do bem, sendo incabível sustentar a insignificância neste tipo de relação.

\footnotetext{
7 Art. 216. Constituem patrimônio cultural brasileiro os bens de natureza material e imaterial, tomados individualmente ou em conjunto, portadores de referência à identidade, à ação, à memória dos diferentes grupos formadores da sociedade brasileira, nos quais se incluem:

I - as formas de expressão;

II - os modos de criar, fazer e viver;

III - as criações científicas, artísticas e tecnológicas;

IV - as obras, objetos, documentos, edificações e demais espaços destinados às manifestações artístico-culturais; $\mathrm{V}$ - os conjuntos urbanos e sítios de valor histórico, paisagístico, artístico, arqueológico, paleontológico, ecológico e científico. (BRASIL, 1988)
} 


\section{O PATRIMÔNIO CULTURAL E A PAISAGEM, A TUTELA PENAL, O PRINCÍPIO DA SOLIDARIEDADE INTERGERACIONAL E A INAPLICABILIDADE DO PRINCÍPIO DA INSIGNIFICÂNCIA}

A paisagem e os bens culturais são parte da representatividade de uma comunidade, são sua riqueza histórica, artística e emocional. Representa a grandiosidade do ser humano, eternizada em elementos que podem eternizar e sobreviver a seus autores, mantendo a herança dos seres humanos de cada tempo. O ordenamento jurídico e com ele a sua vertente mais severa (ultima ratio, o direito penal), que a atua apenas em situações consideradas mais relevantes, deve permitir e garantir que os exemplos possam ser conhecidos e usufruídos pelas gerações do futuro, conforme insculpido no art. 225, caput da CRFB (... proteção do meio ambiente para a presente e as futuras gerações).

O que estabeleceu o constituinte originário foi uma verdadeira solidariedade intergeracional, marcando-a como um princípio regente das condutas de cada geração que estiver sob o referencial deste complexo jurídico-constitucional. Trata-se de princípio expresso, dotado de normatividade, portanto de respeito obrigatório, dotado de "alto nível de generalidade e informadores de todo o ordenamento jurídico", exercendo verdadeira primazia (GRECO, 2007, p. 85). A proteção do patrimônio cultural - e da paisagem - "possibilitará à sociedade manter vínculos com o passado, proporcionando o enraizamento, a manutenção da

história e a memória da sociedade brasileira" (HENKES; GASTAL; MIELKE, 2013, p. 240).

A proteção dos bens culturais e da paisagem é importante para a sadia qualidade de vida das gerações e somente será garantida se cada uma, a seu tempo, propuser-se a tutelá-los de maneira responsável e salvaguardá-los de ações temerárias. Esta atuação traduz o verdadeiro sentido da característica formadora da concepção cultural a solidariedade intergeracional.

Compreende-se a importância e o significado e garante o conhecimento para a geração do amanhã, em um ciclo de ações responsáveis.

Os delitos perpetrados em face do meio ambiente cultural e da paisagem são caracterizados "por uma vitimização de massa, ofendendo, direta ou indiretamente, círculos amplos que justificam uma maior preocupação por parte do Estado inclusive no que tange às futuras gerações, não sendo lícito, [...] a invocação do princípio da insignificância em casos tais" (MIRANDA, 2006, p. 208). Ambos possuem valor intrínseco que não pode ser mensurado, portanto, a sua quantificação para configurar insignificância ou bagatela não é 
possível.

Os danos ao patrimônio cultural e a paisagem atingem as gerações do passado que foram desrespeitadas em seu legado e em sua produção artística e histórica; a geração do presente que se vê vilipendiada social e coletivamente, assim como se vê impossibilitada de conservar o legado para a próxima geração. Com este ato rompe-se com as bases da solidariedade intergeracional, pois não se permite à geração vindoura desfrutar e conhecer a sua origem.

Perde-se por completo o sustentáculo visual da história e da arte de um período, não podendo ser considerado um ato de menor significado, insignificante e ser abrangido por um direito penal mínimo, haja vista que sua repercussão negativa na sociedade apresenta-se como máxima. Tal entendimento é incompatível com os ditames constitucionais.

Por isso,

quando se pensa em conservar esse patrimônio, é preciso ter em mente que o objetivo não pode ser simplesmente manter a dimensão material daqueles bens, mas sim manter os valores por eles representados. Afinal, vão ser aqueles valores que, em última instância, fazem com que aqueles bens sejam considerados parte do patrimônio cultural. (CASTRIOTA, 2009, p. 43).

Uma lesão a valores subjetivos coletivos não pode ser considerada insignificante.

Como compreender o meio ambiente reconhecidamente de fundamental importância para a manutenção da vida na Terra, seja ela biológica ou psíquica como algo de reduzida ou inexpressiva significância. É flagrantemente incompatível.

De tudo que se viu neste estudo, não restam dúvidas sobre a importância do patrimônio cultural e da paisagem para a sociedade. Outro ponto, igualmente, inequívoco é a sua relevância subliminar para as pessoas e para cada geração. A sua significância não está no valor dos objetos, mas, sim, no aspecto subjetivo envolvido na obra de arte ou na construção histórica. Preservá-los repercute na conservação do próprio ser humano, como sujeito no tempo.

Como sustentar que uma análise mental, jurídica e social não singela é insignificante (de bagatela)? Esta reflexão não significa posição contrária aos padrões minimalistas do direito penal, mas, apenas, que devem ser aplicados desde que condizentes com a realidade envolvida.

A amplitude do princípio da insignificância 
está associado a sua aplicação prática. Deve-se agir com cautela, considerando-se insignificante aquilo que realmente o é, sob contemplação objetiva. Em tal particular, o intérprete louvar-se-á no critério o homem médio para considerar o que razoavelmente pode ser tido como delito de bagatela. Eventualmente, poderão ocorrer variações de ordem subjetiva na classificação deste ou daquele fato como insignificante, sendo mesmo possível que se encontre circunstância que se mostre irrelevante, mercê de dado de ordem objetiva. Todavia é necessário rigor na valoração, sob pena do desvirtuamento do real alcance do instituto e da transformação de seu conteúdo em porta aberta para a impunidade. (REBÊLO, 2000, p. 38).

O princípio da insignificância necessita de uma hermenêutica condizente com o direito abrangido. Não se compatibiliza com uma aplicação irrefletida. Precisa de um ajuste preciso à equidade necessária aos valores resguardados pelo Direito Penal e o ordenamento jurídico (REBÊLO, 2000, p. 37). Deverá ser aplicado quando a ação em estudo não atentar contra valores penais, ou seja, valores considerados de especial importância, uma vez que o direito penal somente preocupa-se com as questões e bens jurídicos mais significativos para a coletividade.

Assim, a cultura e a paisagem não são insignificantes jamais, não podendo ser foco de incidência deste conceito, sob pena de desvirtuamento e de perda de memória e identidade para a sociedade. Não se trata, aqui, de direitos disponíveis, ao revés, estuda-se a história, a essência do ser humano, a sua dignidade no mundo - direito indisponível e perpétuo. A história e pertencimento social do ser humano não comportam transações.

\section{CONSIDERAÇÕES FINAIS}

O patrimonial cultural material, os bens que o integram e a paisagem são da responsabilidade de todos e compõem o sustentáculo para que a sociedade reconheça-se e sintase pertencida a uma trajetória legada a ela pelas gerações precedentes. Uma vez reconhecendo a importância do meio ambiente, nele, consequentemente, o meio ambiente cultural, é necessária a proteção penal a seus bens, pois se tornam bens de expressivo significado. Compõem, portanto, o seleto grupo daqueles protegidos pelo direito penal.

O Direito Penal apenas preocupa-se com as questões e bens jurídicos mais relevantes. Por esta razão o meio ambiente cultural e a paisagem foram abrangidos nesta tutela.

Hodiernamente, não restam dúvidas de que o ser humano, assim como o meio ambiente são plúrimos e devem ser compreendidos de maneira holística. Há muito tempo, o meio ambiente não é somente a sua fração natural, mas, sobretudo, a interação do ser humano em sua 
essência com a natureza e as modificações perpetradas. Da mesma maneira, o ser humano não é considerado apenas matéria com liames fisiológicos encadeados, é composto também de subjetividade que carece de amparo para que se mantenha sadio e estável.

O patrimônio cultural e a paisagem encontram-se perfeitamente encaixados nessas duas vertentes, pois são materializados na conexão do ser humano com o ambiente e na importância desta interação para a identificação e edificação de laços de responsabilidade, pertencimento e memória de uma comunidade, de um povo.

Diante deste cenário de especificidades é que surgem as características que, no Direito Penal, particularizam a abrangência da tutela penal, modificando correntes de pensamento majoritárias. Entre elas destaca-se a do direito penal mínimo, pois deve ser abordada nesta seara cum grano salis. O princípio da insignificância é o exemplo mais expressivo, pois na corrente de pensamento descrita alhures ele é referencial para se ter a atuação ou não da esfera penal e o valor do bem cultural e da paisagem não estão em sua repercussão financeira, e, sim, na representatividade temporal e humanística que carregam. Para a adequada proteção, tais parâmetros devem ser deixados de lado e sucumbirem às características inerentes a ambos.

A proteção visa garantir a continuidade e a perpetuação das identidades formadoras do país e da humanidade como um todo, possibilitando uma solidariedade intergeracional neste aspecto.

O respeito a tais características particulares permitirá uma maior proteção dos bens culturais e da paisagem e, via de consequência, a construção de uma sociedade mais aguerrida a seus valores comuns, à sua representatividade histórica e social e a seu pertencimento cultural. Haverá respeito aos caminhos percorridos e aos legados deixados pelas gerações antecedentes, acreditando que foram importantes para o alcance do que se tem hoje, em méritos e deméritos. Nada pode ser reputado de somenos importância nesta seara. Cada elemento constituinte da arte e da história são elementos essenciais para o reconhecimento social e comunitário.

A aplicação do principio da insignificância como reflexo da vertente do direito penal mínimo é equivocada. O objetivo do direito penal mínimo é uma compreensão que engrandeça o homem, acreditando em seu humanismo, mesmo quando acusado de atos ilícitos atentatórios a sociedade. Aplicar tal conceito na própria expressão máxima de humanidade como vestígios artísticos e históricos (meio ambiente cultural) e na paisagem seria minimizar ou desconsiderar o próprio valor base deste pensamento - seria uma aplicação incongruente com a sua própria explicação sociológica e jurídica. 


\section{REFERÊNCIAS}

BLOCH, Marc. Apologia da História ou o Ofício de Historiador. Rio de Janeiro: Jorge Zahar, 2002. 159p.

BRASIL. Lei n. 6938 de 31 de agosto de 1981. Dispõe sobre a Política Nacional do Meio Ambiente, seus fins e mecanismos de formulação e aplicação, e dá outras providências. Disponível em: <http://www.planalto.gov.br/ccivil_03/Leis/L6938.htm>. Acesso em: 29 nov. 2015.

Lei n. 9.605 de 12 de fevereiro de 1998. Dispõe sobre as sanções penais e administrativas derivadas de condutas e atividades lesivas ao meio ambiente, e dá outras providências. Disponível em: <http://www.planalto.gov.br/ccivil_03/LEIS/L9605.htm>. Acesso em: 29 nov. 2015.

$\underset{\text { Disponível }}{ } \cdot$ Constituição (1988). Constituição da República Federativa do Brasil. http://www.planalto.gov.br/ccivil_03/constituicao/ConstituicaoCompilado.htm>. Acesso em: 29 nov. 2015.

CASTRIOTA, Leonardo Barci. Patrimônio Cultural: conceitos, políticas, instrumentos. São Paulo: Annablume; Belo Horizonte: IEDS, 2009. 380p.

Patrimônio Cultural: valores e sociedade civil. In.: MIRANDA, Marcos Paulo de Souza; ARAÚJO, Guilherme Maciel; ASKAR, Jorge Abdo (orgs.). Mestres e Conselheiros: manual de atuação dos agentes do patrimônio cultural. Belo Horizonte: IEDS, 2009. p.40-47.

CHUVA, Márcia. Entre vestígios do passado e interpretações da história - introdução aos estudos sobre patrimônio cultural no Brasil. In.: CUREAU, Sandra; et al. (coords). Um olhar multidisciplinar sobre a efetividade da proteção do patrimônio cultural. Belo Horizonte: Fórum, 2011. p. 37-46.

CUSTODIO, Maraluce Maria. Paisagem : Subsídios para a Construção de um Conceito Democrático no Direito Brasileiro. In: $3^{\circ}$ Colóquio Ibero-Americano Paisagem Cultural, Patrimônio e Projeto - Desafios e Perspectivas, 2014, BELO HORIZONTE. $3^{\circ}$ Colóquio Ibero-Americano Paisagem Cultural, Patrimônio e Projeto - Desafios e Perspectivas. BELO HORIZONTE: IEDS, 2014. v. 1. p. 1-16.

Introdução ao Direito de Paisagem: contribuições ao seu reconhecimento como ciência no Brasil. Rio de Janeiro: Lumen Juris, 2014, 385p.

FIORILlO, Celso Antonio Pacheco; CONTE, Christiany Pegorari. Crimes Ambientais. São Paulo: Saraiva, 2012. 210p.

FREITAS, Vladimir Passos de. A Constituição Federal e a efetividade das normas ambientais. 2. ed. rev.. São Paulo: Revista dos Tribunais, 2002. 248p.

GRECO, Rogério. Curso de Direito: parte geral. 11. ed. Niterói: Impetus, 2009. vol. I. 790p.

Revista Direito Penal, Processo Penal e Constituição -ISSN: 2526 - 0200 | Brasília | v. 2 | n. 1 | p. 808- 825 | Jan/Jun.2016. 
. Principiologia penal e garantia constitucional à intimidade. In.: SCHMITT, Ricardo Augusto (org.). Princípios Penais Constitucionais: direito e processo penal à luz da Constituição Federal. Salvador: Jus Podivm, 2007. p. 83-110.

HENKES, Silviana Lúcia; GASTAL, Alexandre Fernandes; MIELKE, Priscila Venzke. O Direito-Dever à Cultura e à Preservação do Patrimônio Cultural. Veredas do Direito, Belo Horizonte, v.10, n. 20, p. 231-255, julho-dezembro 2013.

IPHAN - INSTITUTO DO PATRIMÔNIO HISTÓRICO E ARTÍSTICO NACIONAL. Paisagem Cultural. Brasilia: Depam / Iphan,2009. Disponível em < http://portal.iphan.gov.br/uploads/ckfinder/arquivos/Livreto_paisagem_cultural.pdf> Acesso em 30/03/2016

MACHADO, Paulo Affonso Leme. Direito Ambiental Brasileiro. 16. ed. São Paulo: Malheiros, 2008. 1126p.

MARCHESAN, Ana, Tutela Judicial do Patrimônio Cultural. In.: SOARES JÚNIOR, Jarbas; MIRANDA, Marcos Paulo de Souza; PITOMBEIRA, Sheila Cavalcanti (coords.). Efetividade da Tutela Ambiental. Belo Horizonte: Del Rey, 2008. p. 127-141.

MILARÉ, Édis. Direito do Ambiente. 9.ed. rev. atual. e ampl.. São Paulo: Revista dos Tribunais, 2014. 1680p.

MIRANDA, Marcos Paulo de Souza. Tutela do Patrimônio Cultural Brasileiro: doutrina, jurisprudência, legislação. Belo Horizonte: Del Rey, 2006. 504p.

. Princípios básicos da proteção ao patrimônio cultural. In.: MIRANDA, Marcos Paulo de Souza; ARAÚJO, Guilherme Maciel; ASKAR, Jorge Abdo (orgs.). Mestres e Conselheiros: manual de atuação dos agentes do patrimônio cultural. Belo Horizonte: IEDS, 2009. p. 15-23.

MONTOLLI, Carolina. A legitimidade jurídica do ambiente face à responsabilização penal e aos direitos da comunidade ambiental. In.: REZENDE, Elcio Nacur; BIZAWU, Kiwonghi (orgs.). Direito Ambiental e Desenvolvimento Sustentável: uma redefinição da consciência ambiental planetária. Belo Horizonte: Escola Superior Dom Helder Câmara ESDHC, 2014. p. 299-315. (Coleção Direito Ambiental e Desenvolvimento Sustentável da Escola Superior Dom Helder Câmara, vol. III).

OLIVEIRA JÚNIOR, Vicente de Paulo Augusto de. A participação da comunidade na proteção ao patrimônio cultural: uma análise do decreto-lei no $25 / 1937$ à luz da Constituição Federal de 1988. Veredas do Direito, Belo Horizonte, v.11, n. 21, p. 215-253, janeiro-junho 2014.

PEREIRA JÚNIOR, Edvaldo Costa. Tutela Penal do Patrimônio Cultural Brasileiro. In.: ALMEID, Gregório Assagra de; SOARES JÚNIOR, Jarbas; MIRANDA, Marcos Paulo de Souza (coords.). Patrimônio Cultural. Belo Horizonte: Del Rey, 2013. p. 259-281. 
PRADO, Luiz Regis. Crimes contra o ambiente: anotações à Lei 9.605, de 12 de fevereiro de 1998. 2. ed. rev. atual. e ampl.. São Paulo: Revista dos Tribunais, 2001. 352p.

REBEÊLO, José Henrique Guaracy. Princípio da Insignificância: interpretação jurisprudencial. Belo Horizonte: Del Rey, 2000. 88p. 